\title{
Sitagliptin Suppresses Active Ghrelin in Patients with Diabetes
}

\author{
Berhane Seyoum*, Alemu Fite and Abdul Abou-Samra
}

Division of Endocrinology, Diabetes and Metabolism, Wayne State University School of Medicine, Detroit, Michigan, USA

\begin{abstract}
Ghrelin is an appetite-stimulating hormone mainly produced by the stomach. Circulating levels of ghrelin increase in fasting sates and fall following meal. Sitagliptin is an orally available new class of anti-diabetic drug that inhibits dipeptidyl peptidase-4 (DPP-4) leading to 2-3 fold increase in the serum concentration of glucagon-like peptide-1 (GLP-1) and glucose-dependent insulinotropic polypeptide (GIP). This study was performed to determine the effects of sitagliptin on circulating levels of ghrelin in control subjects $(\mathrm{N}=15)$ and diabetic patients $(\mathrm{N}=46)$. The diabetic patients were treated with sitagliptin $(\mathrm{N}=15)$, metformin $(\mathrm{N}=16)$ or combination of sitagliptin and metformin $(\mathrm{N}=15)$ for one week. Serum concentrations of total and active ghrelin were determined immediately before and 2 hours after meal challenge. The tests were repeated among patients with diabetes after receiving drug therapy for one week. Active ghrelin was significantly more suppressed than total ghrelin in diabetic patients (by $36 \%, p<0.001$ ). In patients taking sitagliptin, total ghrelin (means \pm SEM) fell from $386 \pm 37 \mathrm{pg} / \mathrm{ml}$ at baseline to $345 \pm 73 \mathrm{pg} / \mathrm{ml}$ whereas active ghrelin decreased from $160 \pm 18 \mathrm{pg} / \mathrm{ml}$ to $85 \pm 12 \mathrm{pg} / \mathrm{ml}(\mathrm{p}<0.01)$. There was no statistical difference in ghrelin levels between the three treatment groups. Active ghrelin concentration correlated negatively with BMI in diabetic patients $(P<0.05)$. After adjusting data for sitagliptin or its combination with metformin suppressed active: total ghrelin ratio more potently than metformin alone $(P<0.001)$. Sitagliptin suppressed active ghrelin more significantly in patients with diabetes when compared to healthy controls. Postprandial ghrelin suppression was strongest after medication. The result of this study warrants further investigation of the significance of ghrelin suppression in patients with diabetes.
\end{abstract}

\section{Introduction}

Ghrelin is a circulating polypeptide hormone derived predominantly from the stomach. It is a peripherally active appetitestimulating hormone [1], which acts at the hypothalamus [2]. Ghrelin is secreted as a large precursor protein- the preproghrelin. As part of posttranslational modification, acyle ghrelin and des-acyle ghrelin are produced [3]. Acylation of ghrelin occurs on Ser3 of the proghrelin peptide by the enzyme ghrelin $\mathrm{O}$-acyltransferase [4,5]. Acylated ghrelin is the active form that binds to its $G$ protein-coupled receptor - the growth hormone secretagogue type 1 a [6] resulting in increased food intake and stimulation of growth hormone secretion [1,2]. The unacylated form, des-n-octanoyl ghrelin, has no physiological activity and, however, is the most abundant in human plasma [7]. The regulation of ghrelin secretion and ghrelin acylation is not well known.

Infusion of ghrelin has been shown to stimulate appetite and increase food intake in healthy volunteers but did not affect gastric emptying suggesting that the effects of ghrelin are centrally mediated rather than secondary to effects on the stomach [8]. Circulating levels of ghrelin increase in fasting states by nearly twofold and fall following meal in a pattern reciprocal to that of insulin [9]. When administered to rodents at supraphysiological doses, ghrelin increases food intake and body weight through the activation of hypothalamic neuropeptide Y [9]. Studies showed that total ghrelin levels inversely correlate with body mass index in conditions of obesity in rodent [10] and humans [11].

Sitagliptin is a recently approved new class of anti-diabetic drug [12]. It is one of the orally available DPP-4 enzyme inhibitors that inactivate GLP-1 and GIP released in response to a meal [13]. As a result of sitagliptin therapy, the serum levels of GLP-1 and GIP increase by 2-3 fold. GLP-1 and GIP potentiate insulin secretion and suppress glucagon release from the pancreas. Stagliptin has no anorexic effect and does not reduce body weight. The effects of sitagliptin on circulating levels of ghrelin have not been studied. However, there are conflicting data in the literature showing increase or decrease in ghrelin in patients treated with metfromin [14-16]. Therefore, in this study we examined the effects of sitagliptin, metformin or their combination on ghrelin concentrations in patients with T2D.

\section{Subjects and Methods}

\section{Patients and controls}

Patients were recruited from the Comprehensive Diabetes Center, of the Wayne State University Physicians Group, Detroit, MI. The study protocol was approved by the Institutional Review Boards of Wayne State University School of Medicine and of the Detroit Medical Center. Informed consent was obtained from all participants. All patients willing to participate in the study were included if they were not taking sitagliptin or metformin previously and if there is no contra-indication for these medications. The patients were divided into 3 groups assigned to treatments with sitagliptin $(\mathrm{N}=15)$, metfromin $(\mathrm{N}=16)$ or combination of metformin and sitagliptin $(\mathrm{N}=15)$. Control subjects consisted of 15 healthy volunteers. The HbA1c for the patients with diabetes ranged between 6.5 to $10 \%$.

\section{Study design}

All subjects had a fasting baseline blood drawing before they start the medication. After the initial blood drawing patients were given a meal challenge in the form of energy drink containing 360 calories

*Corresponding author: Berhane Seyoum, MD, MPH, Division of Endocrinology, Diabetes, and Metabolism, Wayne State University School of Medicine, 4201 St. Antoine, UHC-4H Detroit, MI 48201, USA, Tel: 313-5952830; Fax: 313-993-0903; E-mail: bseyoum@med.wayne.edu

Received November 07, 2011; Accepted December 04, 2011; Published December 08, 2011

Citation: Seyoum B, Fite A, Abou-Samra A (2011) Sitagliptin Suppresses Active Ghrelin in Patients with Diabetes. J Diabetes Metab 2:157. doi:10.4172/21556156.1000157

Copyright: (c) 2011 Seyoum B, et al. This is an open-access article distributed under the terms of the Creative Commons Attribution License, which permits unrestricted use, distribution, and reproduction in any medium, provided the original author and source are credited. 
(Nestle HealthCare Nutrition, Fremont, Michigan). A second blood sample was withdrawn two hours after the meal challenge. Then depending on their blood sugar levels and requirement of medication, patients were started on sitagliptin $100 \mathrm{mg}$ po daily, metformin $500 \mathrm{mg}$ po twice daily or a combination of metformin and sitagliptin (Janumet $50 / 500 \mathrm{mg}$ ) twice daily. After taking the medications for one week patients were invited again for second fasting and post-meal blood drawings as above. Fasting and post-meal challenge ghrelin levels were also determined in healthy volunteers but no drug was given.

\section{Preservation of samples}

Whole blood was directly drawn into a vacutainer tube. The protease inhibitor, 4-(2-aminoethyl) benzenesulfonyl fluoride hydrochloride (AEBSF, $1 \mathrm{mg} / \mathrm{ml}$ ) was added immediately into the collected blood to avoid the break down of ghrelin by proteases. Blood was clotted on ice for $30 \mathrm{~min}$ to 1 hour and centrifuged. Serum was collected and acidified by treating the sample with $0.05 \mathrm{~N} \mathrm{HCl}$ (final concentration). The serum was then frozen at $-80^{\circ} \mathrm{C}$ until analysis.

\section{Ghrelin assay}

ELISA kits used for measurement of total and active serum ghrelin were obtained from Millipore (Millipore, Billerica, MA). The capture and detection antibody mix was applied to $2^{\text {nd }}$ antibody coated 96well ELISA plates specific to either active ghrelin or total ghrelin, containing appropriate quantities of blank, standards, quality controls and samples over 2 hours at RT. The plates were washed with washing buffer and incubated with streptavidin horseradish peroxidase enzyme followed by assay substrate, 3,3',5,5'-tetramethylbenzidine according to the manufacture's instructions. The reaction was stopped after 20 min by addition of stop solution and optical density was measured with a micro-plate reader equipped with SoftMax Pro data acquisition and analysis (Molecular Devices) at $450 \mathrm{~nm}$ and wells corrected for reference $\left(\mathrm{A}_{\text {cor }}=\mathrm{A}_{450}-\mathrm{A}_{570}\right)$.

\section{Statistical analysis}

SPSS software version 18 (SPSS Inc, Chicago, IL) was used for data analysis, data screening, and computations. One way analysis of variance, two-tailed independent unpaired t-tests, means and standard errors of the mean (SEM) were used for continuous variables or parametric tests. Statistical significance was set at $\mathrm{p}<0.05$ for all tests. Each of the three groups was compared with non-diabetic healthy controls.

\section{Results}

The baseline characteristics of the study subjects are shown in table 1 . The mean age of patients was $52.5 \pm 0.9$ years with an average duration of diabetes of $7.9 \pm 0.5$ years; $35 \%$ were male. The mean age of nondiabetic control was $38.9+1.5$ years and $73 \%$ of them were male. The mean BMI was $33.4 \pm 0.5 \mathrm{~kg} \cdot \mathrm{m}^{-2}$ for the patients and $25.3 \pm 0.3$ $\mathrm{kg} \cdot \mathrm{m}^{-2}$ for controls. Patients had mean blood glucose levels of $223.5 \pm$ $6.8 \mathrm{mg} / \mathrm{dL}$ as compared to $97.6 \pm 2.2 \mathrm{mg} / \mathrm{dL}$ for controls (Table 1 ).

A baseline level of active ghrelin was significantly lower among patients with diabetes than that of healthy controls $(\mathrm{P}<0.05)$ whereas total ghrelin was not different between the two groups $(\mathrm{P}=0.46)$. Similarly post-meal challenge levels of active ghrelin were significantly $(\mathrm{p}<0.05)$ lower in diabetic patients than in healthy controls (Figure 1).

In patients taking sitagliptin, total ghrelin levels fell from $386 \pm 37$ $\mathrm{pg} / \mathrm{ml}$ at baseline to $345 \pm 73 \mathrm{pg} / \mathrm{ml}$ ( $11 \%$ drop, $\mathrm{p}>0.05)$ whereas active ghrelin decreased significantly from $160 \pm 18 \mathrm{pg} / \mathrm{ml}$ at baseline to $85 \pm 12$ $\mathrm{pg} / \mathrm{ml}$ (47\% drop, $\mathrm{p}<0.05)$. Patients on metformin and metformin/ sitagliptin combination showed suppression of total ghrelin values from baseline by an average of $31 \%$ and $30 \%$ respectively (Table 2). Similarly, the active ghrelin suppression in patients who took metformin and metformin/sitagliptin combination dropped by $28 \%$ and $33 \%$ respectively from the mean baseline (Table 2). Active ghrelin was more significantly suppressed 2 hours after meal challenge in all patients taking drugs. Sitagliptin alone or in combination with metformin suppressed active serum ghrelin more significantly than metformin alone. Active to total ghrelin ratio further revealed more significant reduction of ghrelin by sitagliptin and/or its combination with metformin than that of metformin alone (Figure 2). Multivariate analysis done to examine the effects of age, BMI, gender, HbAlc and glucose in alerting ghrelin levels did not show any effect.

Active ghrelin concentration correlated negatively with BMI in patients with diabetes but not in healthy control patients.

\section{Discussion}

The study showed that active ghrelin was significantly suppressed in both pre and post-prandial periods in patients with diabetes irrespective of the medicine they took, be it sitagliptin, metformin, or their combination. Active ghrelin levels significantly dropped after one week of treatment. There were no differences in between medications but sitagliptin and it combination with metformin showed more drop in active ghrelin than the group who took metformin only.

In a similar study by Huang et al. [17], pre-prandial ghrelin levels did not change whereas postprandial ghrelin significantly dropped after sitagliptin treatment in healthy non-diabetic subjects. In a similar study, Kiyici et al also showed suppression of active ghrelin by metformin and pioglitazone [18]. English et al also demonstrated significant and

\begin{tabular}{|l|l|l|}
\hline & Control Subjects & Diabetic Patients \\
\hline Number of Subjects & 15 & 46 \\
\hline Age (years) & $38.9 \pm 1.5$ & $52.5 \pm 0.9^{\mathrm{a}}$ \\
\hline Duration of T2DM (years) & $\mathrm{NA}$ & $7.9 \pm 0.5$ \\
\hline BMI $\left(\mathrm{kg} / \mathrm{m}^{2}\right)$ & $25.0 \pm 0.3$ & $33.4 \pm 0.5^{\mathrm{a}}$ \\
\hline Glucose $(\mathrm{mg} / \mathrm{dL})$ & $97.6 \pm 2.2$ & $223.5 \pm 6.8^{\mathrm{a}}$ \\
\hline HbA1c $(\%)$ & $\mathrm{NA}$ & $9.6 \pm 0.1$ \\
\hline Positive family History of T2DM (\%) & $40 \%$ & $78 \% \mathrm{a}^{\mathrm{a}}$ \\
\hline Gender & $73 \%$ male & $35 \%$ male $^{\mathrm{a}}$ \\
\hline
\end{tabular}

${ }^{a} \mathrm{p}<0.05$; diabetic patients versus corresponding values in control subjects. NA data not available or not applicable

Table 1: Baseline characteristics of study subjects (means \pm SEM).

\begin{tabular}{|c|c|c|c|c|c|}
\hline & & Drug & $\mathbf{N}$ & Fasting & Postprandial \\
\hline \multirow{2}{*}{$\begin{array}{l}\text { Before } \\
\text { Treatment }\end{array}$} & Total Ghrelin & NA & 46 & $386 \pm 37$ & $329 \pm 34^{a}$ \\
\hline & $\begin{array}{l}\text { Active } \\
\text { Ghrelin }\end{array}$ & NA & 46 & $160 \pm 18$ & $132 \pm 19^{a}$ \\
\hline \multirow{6}{*}{$\begin{array}{l}1 \text { wk after } \\
\text { treatment }\end{array}$} & \multirow{3}{*}{ Total Ghrelin } & Metformin & 16 & $297 \pm 77^{b}$ & $267 \pm 71^{\mathrm{b}}$ \\
\hline & & Metformin+ Sitagliptin & 15 & $352 \pm 67$ & $269 \pm 79^{\mathrm{ab}}$ \\
\hline & & Sitagliptin & 15 & $420 \pm 78$ & $345 \pm 73^{a b}$ \\
\hline & \multirow{3}{*}{$\begin{array}{l}\text { Active } \\
\text { Ghrelin }\end{array}$} & Metformin & 15 & $148 \pm 43^{\text {bc }}$ & $115 \pm 32^{\mathrm{abc}}$ \\
\hline & & Metformin+Sitagliptin & 15 & $177 \pm 45^{c}$ & $107 \pm 22^{\mathrm{abc}}$ \\
\hline & & Sitagliptin & 14 & $113 \pm 23^{b}$ & $85 \pm 12^{\mathrm{ab}}$ \\
\hline
\end{tabular}

*Statistics is computed on weighted mean multiple comparison (ANOVA) ${ }^{a} \mathrm{p}<0.05$; postprandial versus fasting

${ }^{\mathrm{b}} \mathrm{p}<0.05$; after medication versus corresponding value before medication ${ }^{c} \mathrm{p}<0.05$; medication versus sitagliptin alone

Table 2: Total and active ghrelin levels $(\mathrm{pg} / \mathrm{mL})$ before and after treatment $($ mean \pm SEM)*. 

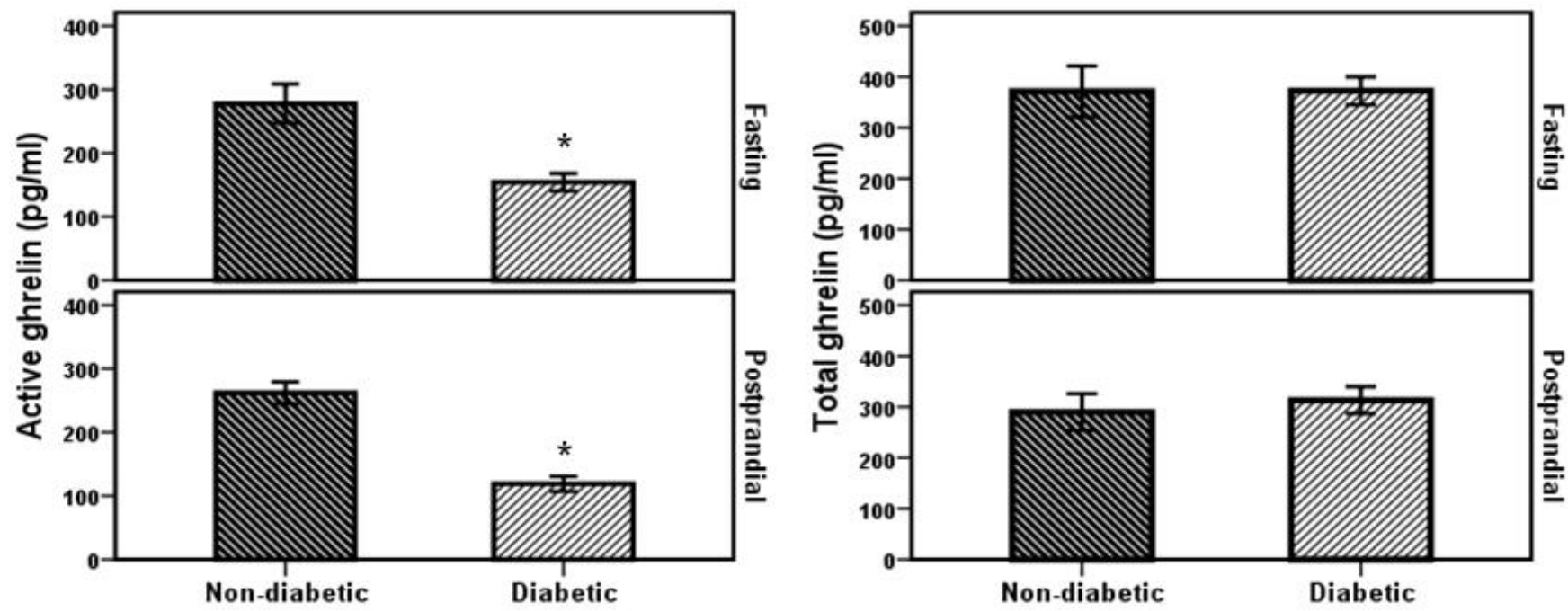

${ }^{*} \mathrm{p}<0.001$

Figure 1: Alteration of serum ghrelin in response to meal challenge that contain 360 calories. Ghrelin was measured in fasting state and 2 hours after meal challenge. Total and active ghrelin levels were compared between diabetic patients and non-diabetic controls.

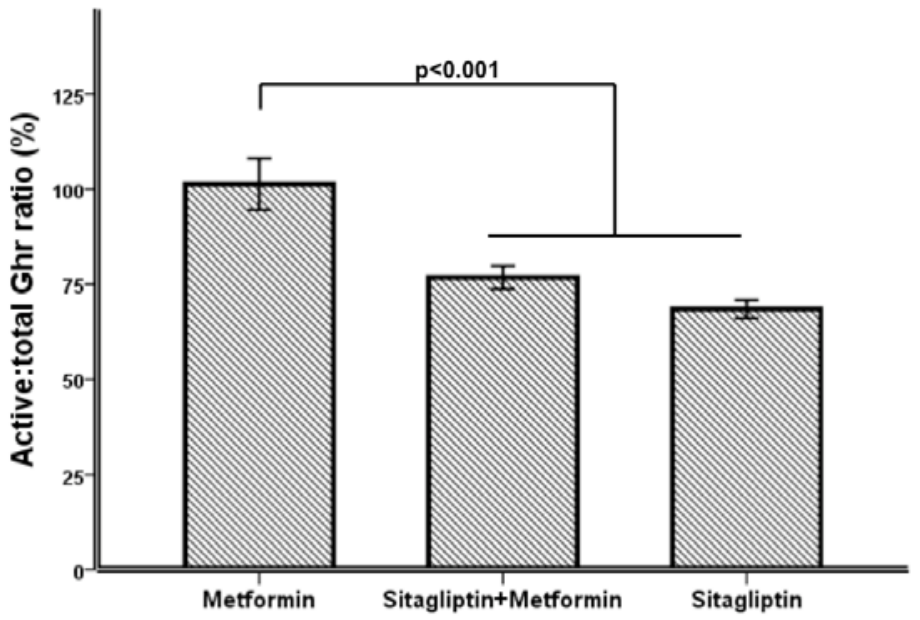

Figure 2: Alteration of serum ghrelin in response to different medications. Serum active:total percent ghrelin ratios were compared among patients with diabetes in different treatment groups.

prolonged postprandial suppression of ghrelin among patients taking metformin when compared to patients not taking metformin [15]. However, fasting ghrelin increased after metformin therapy in patients with polycystic ovary syndrome [14]. Contrary to our finding, Doogue et al found an increase in postprandial ghrelin level after patients were treated with metformin for 6 weeks.

After controlling for BMI, patients with diabetes were significantly different from those without diabetes in the levels of serum ghrelin. An inverse correlation was found between serum ghrelin and BMI for patients with diabetes, who were generally obese. This is in agreement with earlier studies reported by Tschop et al. [11] who showed that obese subjects have lower plasma concentrations of ghrelin than agematched lean control subjects. These may suggest that ghrelin is down regulated in human obesity as a consequence of elevated factors such as insulin or leptin levels perhaps representing a physiological adaptation to the positive energy balance associated with obesity. The result of this study was also in agreement with the fact that ghrelin levels rise in situations prior to meals, following food deprivation and in response to weight loss $[9,19]$. Rising fasting ghrelin or ghrelin administration stimulates feeding and lowers energy expenditure $[7,11,14]$. Ghrelin may function as an anabolic signal molecule during energy depletion and catabolic signal during energy excess through insulin synthesis and secretion.

It should be noted that this study has limitations, which could bias our conclusions. The healthy non-diabetic subjects do not provide a perfect control to the diabetic patients in terms of the demographic characteristics such as age, gender and BMI. The diabetic patients were generally older, predominantly female and overweight. In addition the study is limited by the small number of patients and controls.

In conclusion, diabetic patients on sitagliptin and metformin either alone or in combination lowered levels of serum ghrelin compared to non-diabetic controls. Active ghrelin was more responsive to meal 
Citation: Seyoum B, Fite A, Abou-Samra A (2011) Sitagliptin Suppresses Active Ghrelin in Patients with Diabetes. J Diabetes Metab 2:157. doi:10.4172/2155-6156.1000157

Page 4 of 4

challenges and anti-diabetic therapy. Suppression of serum ghrelin was found to be strongest after meal challenge. The result of this study warrants further investigation of the significance of ghrelin suppression in patients with diabetes.

\section{Acknowledgment}

The study was supported in part by a research grant from the InvestigatorInitiated Studies Program of Merck \& Co., Inc. The opinions expressed in this paper are those of the authors and do not necessarily represent those of Merck \& Co., Inc.

\section{References}

1. Kojima M, Hosoda H, Date $Y$, Nakazato M, Matsuo H, et al. (1999) Ghrelin is a growth-hormone-releasing acylated peptide from stomach. Nature 402: 656660 .

2. Wren AM, Small CJ, Ward HL, Murphy KG, Dakin CL, et al. (2000) The nove hypothalamic peptide ghrelin stimulates food intake and growth hormone secretion. Endocrinology 141: 4325-4328.

3. Hosoda H, Kojima M, Mizushima T, Shimizu S, Kangawa K, et al. (2003) Structural divergence of human ghrelin. Identification of multiple ghrelin-derived molecules produced by post-translational processing. J Biol Chem 278: 64-70.

4. Gutierrez JA, Solenberg PJ, Perkins DR, Willency JA, Knierman MD, et al (2008) Ghrelin octanoylation mediated by an orphan lipid transferase. Proc Natl Acad Sci U S A 105: 6320-6325.

5. Yang J, Brown MS, Liang G, Grishin NV, Goldstein JL (2008) Identification of the acyltransferase that octanoylates ghrelin, an appetite-stimulating peptide hormone. Cell 132: 387-396.

6. Bednarek MA, Feighner SD, Pong SS, McKee KK, Hreniuk DL, et al. (2000) Structure-function studies on the new growth hormone-releasing peptide, ghrelin: minimal sequence of ghrelin necessary for activation of growth hormone secretagogue receptor 1a. J Med Chem 43: 4370-4376.

7. Hosoda H, Kojima M, Matsuo H, Kangawa K (2000) Ghrelin and des-acyl ghrelin: two major forms of rat ghrelin peptide in gastrointestinal tissue. Biochem Biophys Res Commun 279: 909-913.

8. Wren AM, Seal LJ, Cohen MA, Brynes AE, Frost GS, et al. (2001) Ghrelin enhances appetite and increases food intake in humans. J Clin Endocrino Metab 86: 5992.

9. Cummings DE, Purnell JQ, Frayo RS, Schmidova K, Wisse BE, et al. (2001) A preprandial rise in plasma ghrelin levels suggests a role in meal initiation in humans. Diabetes 50: 1714-1719.

10. Tschöp M, Smiley DL, Heiman ML (2000) Ghrelin induces adiposity in rodents Nature 407: 908-913.

11. Tschöp M, Weyer C, Tataranni PA, Devanarayan V, Ravussin E, et al. (2001) Circulating ghrelin levels are decreased in human obesity. Diabetes 50: 707709 .

12. Drucker D, Easley C, Kirkpatrick P (2007) Sitagliptin. Nat Rev Drug Discov 6 109-110.

13. Herman GA, Bergman A, Liu F, Stevens C, Wang AQ, et al. (2006) Pharmacokinetics and pharmacodynamic effects of the oral DPP-4 inhibitor sitagliptin in middle-aged obese subjects. J Clin Pharmacol 46: 876-886.

14. Schöfl C, Horn R, Schill T, Schlösser HW, Müller MJ, et al. (2002) Circulating ghrelin levels in patients with polycystic ovary syndrome. J Clin Endocrino Metab 87: 4607-4610.

15. English PJ, Ashcroft A, Patterson M, Dovey TM, Halford JC, et al. (2007) Metformin prolongs the postprandial fall in plasma ghrelin concentrations in type 2 diabetes. Diabetes Metab Res Rev 23: 299-303.

16. Doogue MP, Begg EJ, Moore MP, Lunt H, Pemberton CJ, et al. (2009) Metformin increases plasma ghrelin in Type 2 diabetes. $\mathrm{Br} \mathrm{J}$ Clin Pharmaco 68: 875-882

17. Huang CL, Hsu CH, Huang KC, Su HY, Weng SF (2010) Preprandial single ora dose of sitagliptin does not affect circulating ghrelin and gastrin levels in normal subjects. Pharmacology 85: 131-135.

18. Kiyici S, Ersoy C, Oz Gul O, Sarandol E, Demirci M, et al. (2009) Total and acylated ghrelin levels in type 2 diabetic patients: similar levels observed after treatment with metformin, pioglitazone or diet therapy. Exp Clin Endocrino Diabetes 117: 386-390.

19. Nagaya N, Uematsu M, Kojima M, Date Y, Nakazato M, et al. (2001) Elevated circulating level of ghrelin in cachexia associated with chronic heart failure: relationships between ghrelin and anabolic/catabolic factors. Circulation 104: 2034-2038. 